\title{
Article \\ The FBA Motif-Containing Protein NpFBA1 Causes Leaf Curling and Reduces Resistance to Black Shank Disease in Tobacco
}

\author{
Zhongyi Xie ${ }^{1,2,+} \mathbb{D}$, Guo Wen ${ }^{1,2,3,+}+\mathbb{D}$, Yao Yang ${ }^{1,2}$, Haiyan Wang ${ }^{1,2} \mathbb{D}$, Jinying Wang ${ }^{1,2}$, Chenggong Lei ${ }^{1,2}$, \\ Qigao Guo ${ }^{1,2}$, Jiangbo Dang ${ }^{1,2, *(\mathbb{D})}$ and Guolu Liang ${ }^{1,2, *(\mathbb{D})}$
}

1 Key Laboratory of Horticulture Science for Southern Mountains Regions of Ministry of Education, College of Horticulture and Landscape Architecture, Southwest University, Chongqing 400715, China; xzy960526@163.com (Z.X.); guowen2020@126.com (G.W.); yangyao0814@126.com (Y.Y.); wwwhy157@163.com (H.W.); wangjinying327@126.com (J.W.); lcg488531820@163.com (C.L.); qgguo75@swu.edu.cn (Q.G.)

2 State Cultivation Base of Crop Stress Biology for Southern Mountainous Land, Academy of Agricultural Sciences, Southwest University, Chongqing 400715, China

3 College of Horticulture, China Agricultural University, Beijing 100193, China

* Correspondence: dangjiangbo@126.com (J.D.); lianggl@swu.edu.cn (G.L.); Tel.: +86-023-68250383 (J.D.); +86-023-68250383 (G.L.)

+ These authors contributed equally to this work.

Citation: Xie, Z.; Wen, G.; Yang, Y.; Wang, H.; Wang, J.; Lei, C.; Guo, Q.; Dang, J.; Liang, G. The FBA MotifContaining Protein NpFBA1 Causes Leaf Curling and Reduces Resistance to Black Shank Disease in Tobacco. Agronomy 2021, 11, 2478. https:// doi.org/10.3390/agronomy11122478

Academic Editor: Mamoru Okamoto

Received: 13 October 2021

Accepted: 2 December 2021

Published: 6 December 2021

Publisher's Note: MDPI stays neutral with regard to jurisdictional claims in published maps and institutional affiliations.

Copyright: (c) 2021 by the authors. Licensee MDPI, Basel, Switzerland. This article is an open access article distributed under the terms and conditions of the Creative Commons Attribution (CC BY) license (https:// creativecommons.org/licenses/by/ $4.0 /)$.

\begin{abstract}
Plant leaf morphology has a great impact on plant drought resistance, ornamental research and leaf yield. In this study, we identified a new gene in Nicotiana plumbaginifolia, NpFBA1, that causes leaf curl. The results show that the NpFBA1 protein contains only one unique F-box associated (FBA) domain and does not have an F-box conserved domain. Phylogenetic analysis placed this gene and other Nicotiana FBA genes on a separate branch, and the NpFBA1 protein localized to the nucleus and cytoplasm. The expression of NpFBA1 was induced by black shank pathogen (Phytophthora parasitica var. nicotianae) infection and treatment with salicylic acid (SA) and methyl jasmonate (MeJA). NpFBA1-overexpressing transgenic lines showed leaf curling and aging during the rosette phase. During the bolting period, the leaves were curly and rounded, and the plants were dwarfed. In addition, $N p F B A 1$-overexpressing lines were more susceptible to disease than wild-type (WT) plants. Further studies revealed that overexpression of $N p F B A 1$ significantly downregulated the expression of auxin response factors such as NtARF3 and the lignin synthesis genes $N t P A L, N t C 4 H$, $N t C A D 2$, and $N t C C R 1$ in the leaves. In conclusion, $N p F B A 1$ may play a key role in regulating leaf development and the response to pathogen infection.
\end{abstract}

Keywords: Nicotiana plumbaginifolia; NpFBA1; overexpression; leaf curling; susceptibility

\section{Introduction}

The ubiquitin-proteasome system (UPS) is the predominant proteolytic pathway within eukaryotes. Ubiquitin is activated by covalent ligation to ubiquitin activating enzyme (E1), transferred to ubiquitin conjugating enzyme (E2) and added to ubiquitin ligase (E3), and then the ubiquitin labeled target protein is recognized and degraded by the $26 S$ proteom [1]. The UPS regulates key physiological processes in plants, such as growth and development, hormone signaling, self-incompatibility, and resistance to pathogen invasion [2]. The F-box protein binds to the S-phase kinase-associated protein 1 (SKP1), cullin1 (CUL1) and RING-box protein (RBX) to form an E3 called the SCF complex that specifically recognizes the degradation substrate [3]. The selection of targeted substrates is often determined by the secondary domain of the F-box protein (FBP) [4]. The F-boxassociated (FBA) domain often appears as the C-terminal secondary domain of the F-box protein. In addition, secondary domains of the F-box include leucine zipper (LRR), WD 
repeats and Kelch [5]. Due to the diversity of the C-terminal secondary structure of the F-box protein, a large number of different SCF complexes can be formed in plants. These complexes can specifically recognize different target proteins and participate in the regulation of many physiological phenomena, including hormone signaling responses, light signaling responses, biological clocks, flowering time and disease resistance responses. Therefore, it is important to explore the functions of these secondary domains.

Although the FBA gene family is the largest FBP subfamily in Arabidopsis [6], few studies have been conducted on its function. At present, the study of FBA family function mainly focuses on two aspects: the regulation of plant growth and development and the regulation of the defense response involved in plant disease resistance. Many studies in recent years have suggested that FBA subfamily units positively or negatively regulate plant growth and development by the targeted degradation of certain hormone response factors. Gibberellins (GAs) are central regulators during plant growth and development, regulating seedling growth, leaf development, root and stem growth, and other processes. However, there is also a negative series of negative regulators in the GAs metabolic pathway, such as DELLA proteins gibberellin insensitive (GAI), a repressor of ga1-3 (RGA) [7-9]. In rice, Arabidopsis, and barley, the GA-induced decrease in DALLE levels is dependent on $26 \mathrm{~S}$ proteasome function [10]. In gibberellin-insensitive dwarf 2 (GID2), encoding an F-box protein in rice interacts with DELLA protein Slender Rice 1 (SLR1), a negative regulator of GAs, and triggers ubiquitin-mediated SLR1 degradation, thereby maintaining the normal height phenotype in rice [11]. In addition, studies have revealed an FBA gene, Slfbf, to be a key regulator of pollen development in tomato and that this gene responds to GAs [12].

Auxin regulates the differentiation and elongation of plant cells, plays an extremely important role in plant growth and development, and is regulated by two protein families, namely, Auxin/indole-3-acetic acid (AUX/IAAs) and auxin response factors (ARFs). It has been shown that auxin promotes the binding of the F-box protein TIR1 to the Aux/IAA protein to cause degradation of the $26 \mathrm{~S}$ proteasome, thus relieving the inhibitory effect of Aux/IAA on ARFs and in turn enabling plants to undergo normal transcription $[13,14]$. The operation of genes involved in auxin biosynthesis, degradation, and binding results in abnormal leaf development, including wrinkled, rounded, and coiled leaf phenotypes $[15,16]$. Therefore, some F-box proteins are essential for maintaining normal leaf development. Arabidopsis MicroRNA394 and its target gene, the F-box gene LEAF CURLING RESPONSIVENESS, LCR, regulate leaf curling-related morphology [17]. Auxin-signaling F-box protein 4 (AFB4) mutants show smaller leaves, shorter stems, increased leaf thickness and resistance to disease [18]. In Arabidopsis, site-directed mutations and knockdown demonstrate that the FBA domain is indispensable for the normal regulation of leaf morphology and that regulation of this trait is likely related to plant defense [19]. In addition, the FBA gene has been reported to play an important role in signaling pathways such as the salicylate (SA), ethylene, and abscisic acid (ABA) pathways [20-22].

In recent years, FBA gene mutants have become an important material for studying the plant defense response, and most FBA gene mutations can enhance plant resistance. The Arabidopsis F-Box protein suppressor of nim1-1 (SON1) has been reported to regulate a novel defense response that negatively regulates plant resistance through the UPS pathway, independent of system-acquired resistance (SAR) [23]. Similarly, in research using cpr30 mutants as subjects, the F-box protein CPR30 was found to be a novel negative regulator inhibiting the accumulation of the R protein, which regulates both SA dependent defense signals and SA-independent defense signals and is likely regulated by the ubiquitinproteasome pathway in Arabidopsis [24]. Most current reported results suggest that FBA family genes negatively regulate the defense response in plants.

The results of recent studies all indicate the key role of the FBA domain in plant growth and pathogen defense. However, the currently reported proteins are mostly FBA proteins containing F-box motifs, and few have been reported to contain only FBA domain gene functions. In this study, an FBA gene was isolated from Nicotiana plumbaginifolia, 
and the effect of this gene on leaf morphological development and Phytophthora parasitica defense was initially examined.

\section{Materials and Methods}

\subsection{Plant Materials}

Seeds of the N. tabacum variety 'Honghuadajinyuan' $(2 \mathrm{n}=4 \mathrm{x}=48)$ and N. plumbaginifolia $(2 n=2 x=20)$ were provided by the National Medium Tobacco Intermediate Bank and later cultivated and harvested by the authors. Seeds of $N$. benthamiana were obtained from this laboratory. The seeds of $N$. tabacum and $N$. benthamiana were seeded directly in sterilized soil, dormant seeds of N. plumbaginifolia were placed on wet filter paper and treated with $100 \mu \mathrm{M}$ gibberellic acid (GA3) [25], and the germinated seeds were then moved to sterilized soil. The tobacco materials were grown under the following growth chamber conditions: temperature of $24^{\circ} \mathrm{C}$ and long-day photoperiod (16 h light $/ 8 \mathrm{~h}$ dark). N. plumbaginifolia material was used for gene cloning and spatiotemporal expression, N. tabacum was used for transgene tests, and N. benthamiana was used for transient expression.

\subsection{Culture of Pathogens and Production of Spore Suspension}

P. parasitica var. nicotiana was provided by Professor Zhenlun Li, School of Resources and Environment of Southwest University, and originally collected from Fengjie County, Chongqing. Pathogens were grown on oat agar medium for 2 weeks, and the hyphae were scraped down and placed in $0.1 \% \mathrm{KNO}_{3}$ solution for 3 days. Hyphae were ground after storage at $4{ }^{\circ} \mathrm{C}$ for $30 \mathrm{~min}$ [26], the mycelium was later filtered with a mesh filter, the filtered spore suspension was placed under a microscope, and the number of sporocysts was recorded with a cell count plate. The sporocyst concentration of the sporulation suspension was finally adjusted to $1.4 \times 10^{3}$ sporangium $\cdot \mathrm{ml}^{-1}$ for tobacco invasion experiments.

\subsection{RNA Extraction and cDNA Synthesis}

RNA from 2-month-old N. plumbaginifolia was extracted with an RNA extraction kit (DP441, TIANGEN, Beijing, China) and RNA mass and concentration were detected by $1 \%$ agarose gel electrophoresis and a 2100 Bioanalyzer (Agilent Technologies, Santa Clara, CA, USA), respectively. First-strand cDNA was synthesized by using a PrimeScript ${ }^{\mathrm{TM}}$ RT reagent Kit with gDNA Eraser (RR047A, TAKARA, Shiga, Japan).

\subsection{NpFBA1 Cloning and Sequence Analysis}

Homologous cloning was performed using primers designed for the UTR of the N. tabacum FBA gene (XM_009598194), and then specific primers were designed (Supplementary Table S2) for the ORF region of the amplified sequences to eventually obtain the complete sequence of the N. plumbaginifolia FBA gene. All polymerase chain reaction (PCR) products were cloned into PMD19-T easy vector (TAKARA) for sequencing. The deduced amino acid sequences were aligned using the ClustalW program. A phylogenetic tree was constructed using MEGA 5.0 with the neighbor-joining method with 1000 bootstrap replicates with other sequences (Supplementary Table S3).

\subsection{Subcellular Localization of NpFBA1 Proteins}

The NpFBA1 sequences without a stop codon were linked to the pCAMBIA 2300-GFP vector using seamless cloning. Specific primers with restriction enzyme sites (BamHI) are listed in Supplementary Table S4. The constructed NpFBA1-GFP fusion protein and empty vector were then transformed into the Agrobacterium rhizomis strain (GV3101) and injected into the lower epidermis at $\mathrm{OD}=0.1$ with a needle-free syringe. After $48-72 \mathrm{~h}$ in the dark culture, the epidermis was removed to capture the fluorescence signal under an Observer DP80 fluorescence microscope (Olympus, Tokyo, Japan). Random fluorescent tobacco epidermal cells were captured with a charge-coupled device camera. 


\subsection{Hormone Treatment and Pathogen Infection}

Two-month-old N. plumbaginifolia was treated with SA $(2 \mathrm{mM})$ and methyl jasmonate (MeJA) $(1 \mathrm{mM})$ hormones, with $0.1 \%$ alcohol treatment as a control. Each treatment was performed in triplicate, and the hormones were sprayed until the leaves bore water droplets. The leaves were taken at 0,6,12, 24, 48, and $72 \mathrm{~h}$ after treatment and frozen with liquid nitrogen.

N. plumbaginifolia leaves were taken for an isolated pathogen infection assay with three replicates. The leaf surface of the tobacco was punctured with five bound needles, $50 \mu \mathrm{L}$ of the prepared spore suspension was placed on the wound of the leaves, and filter paper was placed over the wound to maintain moisture and prevent evaporation of the spore suspension. The leaves were taken at $0,6,12,18,24,36,48$ and $72 \mathrm{~h}$ and frozen with liquid nitrogen.

\subsection{NpFBA1 Gene Expression Vector Constructs and the Acquisition of Transgenic Tobacco}

pCAMBIA2300-NpFBA1 was constructed by linking the NpFBA1 gene of the cloned vector to the pCAMBIA2300 vector using seamless ligation BamHI (Supplementary Table S4). The constructed recombinant vector was transformed into the Agrobacterium LBA4404 strain and used to infect tobacco $(\mathrm{OD}=0.8)$ by the leaf dish transformation method [27]. Tobacco leaf dish were placed into pre-medium to avoid light culture for $1 \mathrm{~d}$. Leaf dish were transferred to screening medium, grown for approximately $20 \mathrm{~d}$, and transferred to root medium. Rooted resistant plants were selected for cultivation, the medium was washed away, and the plants were transferred to soil for growth (temperature, $24{ }^{\circ} \mathrm{C} ; 16 \mathrm{~h}$ light and $8 \mathrm{~h}$ dark). Finally, we identified transgenic lines by PCR. Pre-medium: $2.29 \mathrm{~g} \cdot \mathrm{L}^{-1}$ Murashige \& Skoog medium (MS) $+30 \mathrm{~g} \cdot \mathrm{L}^{-1}$ sucrose $+2.0 \mathrm{mg} \cdot \mathrm{L}^{-1}$ 6-benzyl aminopurine $(6-\mathrm{BA})+0.5 \mathrm{mg} \cdot \mathrm{L}^{-1}$ naphthylacetic acid (NAA) $+6.25 \mathrm{~g} \cdot \mathrm{L}^{-1}$ agar. Screening medium: $2.29 \mathrm{~g} \cdot \mathrm{L}^{-1} \mathrm{MS}+30 \mathrm{~g} \cdot \mathrm{L}^{-1}$ sucrose $+2.0 \mathrm{mg} \cdot \mathrm{L}^{-1} 6-\mathrm{BA}+0.5 \mathrm{mg} \cdot \mathrm{L}^{-1} \mathrm{NAA}+500 \mathrm{mg} \cdot \mathrm{L}^{-1}$ carbenicillin $(\mathrm{Cb})+50 \mathrm{mg} \cdot \mathrm{L}^{-1}$ kanamycin $(\mathrm{Kan})+6.25 \mathrm{~g} \cdot \mathrm{L}^{-1}$ agar; root medium: $2.29 \mathrm{~g} \cdot \mathrm{L}^{-1}$ $\mathrm{MS}+30 \mathrm{~g} \cdot \mathrm{L}^{-1}$ sucrose $+250 \mathrm{mg} \cdot \mathrm{L}^{-1} \mathrm{Cb}+50 \mathrm{mg} \cdot \mathrm{L}^{-1} \mathrm{Kan}+6.25 \mathrm{~g} \cdot \mathrm{L}^{-1}$ agar.

\subsection{DNA Extraction from Transgenic and Wild Tobacco}

The leaves of 2-month-old transgenic tobacco and wild-type (WT) tobacco were ground with liquid nitrogen, and then the genomic DNA of tobacco was extracted by modified CTAB method [28]. The detection method of DNA quality and concentration, refer to 2.1, and high-quality gDNA was diluted to $50 \mathrm{ng} \cdot \mu \mathrm{L}^{-1}$ for PCR analyses. Primer pCAMBIA2300- NpFBA1 was used to identify transgenic plants.

\subsection{Quantitative Real-Time Polymerase Chain Reaction ( $q R T-P C R$ )}

qRT-PCR was conducted to detect changes in gene expression by using qTOWER $^{3} \mathrm{G}$ (Analytik Jena, Jena, Germany). The PCR amplification procedure was as follows: $95^{\circ} \mathrm{C}$ for $30 \mathrm{~s}$, followed by 40 rounds of $95{ }^{\circ} \mathrm{C}$ for $20 \mathrm{~s}, 56{ }^{\circ} \mathrm{C}$ for $60 \mathrm{~s}$, and a melting cycle of $65 \sim 95^{\circ} \mathrm{C}$. The system was a Novo Startfi SYBR qPCR SuperMix Plus $10 \mu \mathrm{L}$ system (E09601A, Novoprotein, Shanghai, China). The $-\Delta \Delta \mathrm{CT}$ method [29] was used to calculate the relative expression values, $N p E F-1 a$ and $N t E F-1 a$ were used as controls of $N$. plumbaginifolia and N. tabacum, respectively [30]. qRT-PCR analysis was repeated using three technical replicates. All the primers for qRT-PCR are shown in Supplementary Table S5.

\subsection{Leaf Anatomy Observation}

The tips of three mature leaves per plant were prepared for paraffin sections, cut into $0.5 \mathrm{~cm}^{2}$ square blocks and then fixed with $24 \mathrm{~h}$ paraffin sections in FAA fixation solution with reference to previous methods [31]. Tobacco leaf thickness, fence tissue thickness, fence tissue density, sponge tissue thickness, and upper and lower epidermal cell thickness were observed under an Olympus fluorescence microscope, and each indicator of the leaves was measured by using the ruler in the photos taken by a charge-coupled device camera. Ten visual fields per leaf and three observations per visual field were used to calculate the 
average and deviation of each index. The cell tense ratio (CTR) and spongy ratio (SR) were calculated by the following formula: CTR $\%=$ fence tissue thickness $/$ leaf thickness $\times 100$; $\mathrm{SR} \%=$ sponge tissue thickness /leaf thickness $\times 100$.

\subsection{Calculation of Leaf Damage Area after P. parasitica Infection}

Transgenic tobacco leaves were collected, infected (refer to 2.6), photographed at 0, 1, 2, 3, 4, and 5 days post inoculation(dpi) and analyzed with Adobe Photoshop CS3.

\section{Results}

\subsection{Identification of the NpFBA1 Gene from Nicotiana plumbaginifolia}

Based on homologous cloning techniques we isolated an FBA gene in N. plumbaginifolia, and named it NpFBA1 (Genbank accession number: OK216143). The alignment of NpFBA1 to the mRNA of the common tobacco FBA gene revealed that it has a base insertion at 651 $\mathrm{bp}$, which results in a backward shift of stop codons and altered amino acid sequences, which may cause large functional differences. Amino acid sequence analysis showed that the NpFBA1 protein encodes 317 amino acids with a calculated molecular weight (MW) of $37.2 \mathrm{kDa}$ and a deduced isoelectric point (PI) of 8.89, containing a conserved FBA domain (Figure 1A).

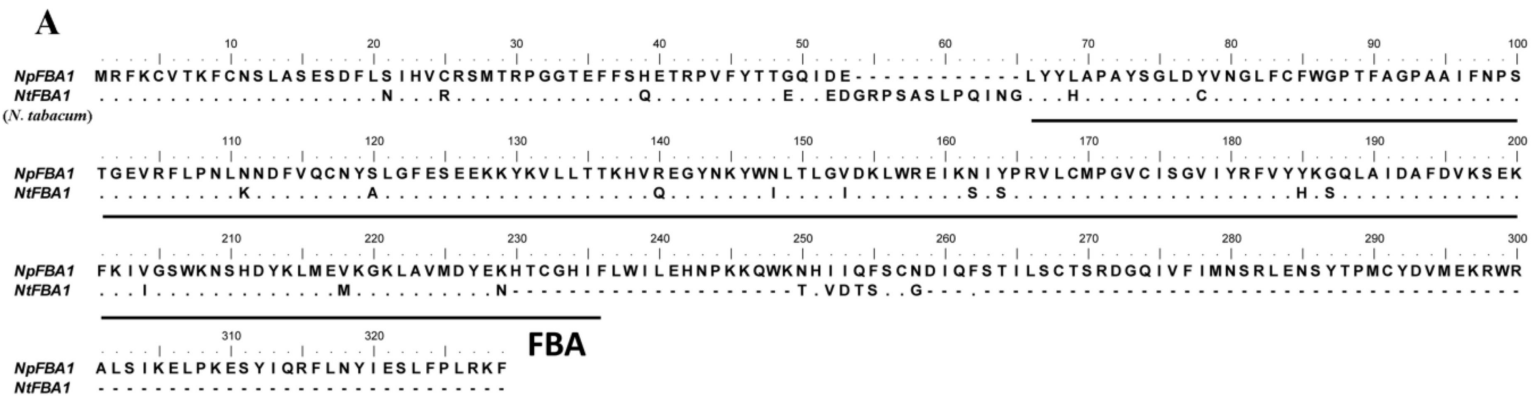

B

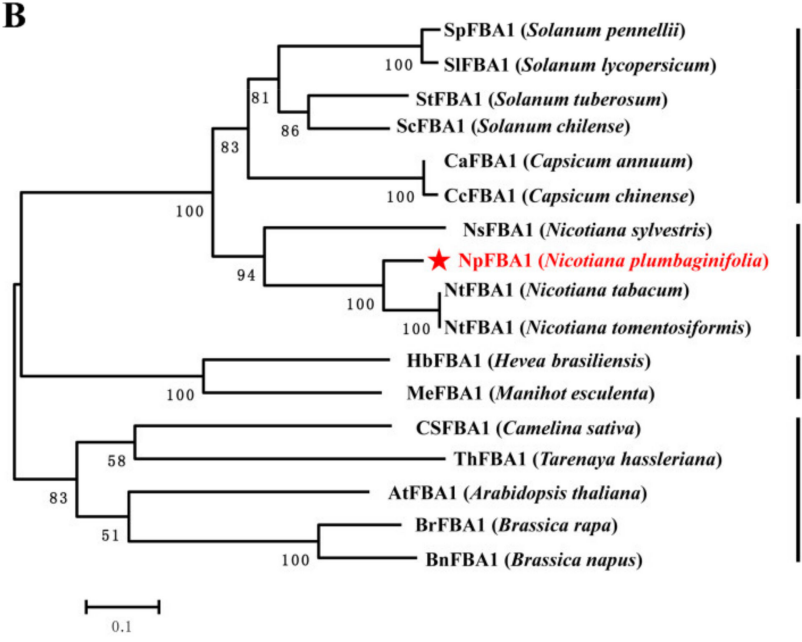

C

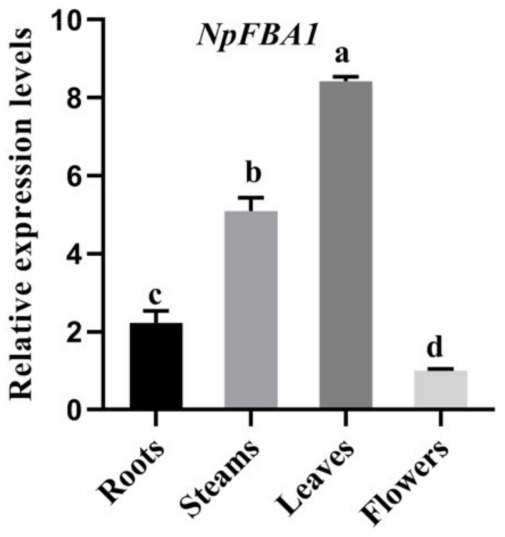

Figure 1. Characterization of $N p F B A 1$. (A) Blast analysis of the $N p F B A 1$ amino acid sequence and NtFBA1 protein sequence, and the black underline represents the FBA conserved domain of NpFBA1. (B) Phylogenetic tree of the NpFBA1 protein and FBA proteins in other plants. (C) Expression of NpFBA1 in different tissues of N. plumbaginifolia (number of samples, $\mathrm{n}=10$ ). The letters above the bars indicate significant differences at $p<0.05$ (Duncans multiple comparison test).

To reveal the evolution of $N p F B A 1$, BLAST was performed with cloned $N p F B A 1$ sequences and 16 homologues from other angiosperms. Phylogenetic trees of amino acid sequences of FBA gene in N. plumbaginifolia and other plants divided them into four groups based on genetic relationships (Figure 1B). The NpFBA1 protein is located in the same clade (group II) as the FBA proteins of Nicotiana tabacum, Nicotiana tomentosiformis, and Nicotiana 
sylvestris, and domain analysis shows that this group contains only one FBA domain and no other domains. NpFBA1 is most closely related to the homologues in N. tabacum and $N$. tomentosiformis. The amino acid sequence of the FBA protein in N. tabacum was identical to that in N. tomentosiformis, which might indicate that the FBA gene of N. tabacum was derived from $N$. tomentosiformis. NpFBA1 is closely related to FBA genes in other Solanaceae plants, such as tomato and potato, and their FBA genes were placed in the same large clade (group I). The Hevea brasiliensis and Manihot esculenta FBA genes were located in the same clade (group III), and the FBA genes of the Camelina sativa, Tarenaya hassleriana, Arabidopsis thaliana, Brassica rapa, and Brassica napus were located in the same clade (group IV).

The tissue specificity of gene expression provides reference information for predicting and studying the biological functions of genes. We also examined the expression pattern of $N p F B A 1$ in specific tissues, including roots, stems, leaves and flowers (Figure 1C). We took the NpEF-1a gene of N. plumbaginifolia as the control gene, the expression level of NpFBA1 of flowers as unit 1 , and the relative expression level was calculated by qPCR results using $-\triangle \triangle C T$ method. The results showed that $N p F B A 1$ was expressed in all of these tissues. The highest and lowest expression levels were observed in leaves and flowers, respectively. In addition, there were significant differences among roots, stems, leaves and flowers.

\subsection{Subcellular Localization of NpFBA1}

To determine the subcellular location of NpFBA1, we constructed a 35S::NpFBA1-GFP fusion controlled by the CaMV 355 promoter. The recombinant fusion vector and the control vector (35S::GFP) were transferred into the young leaves of tobacco (Nicotiana benthamiana) by Agrobacterium-mediated transformation. Then, the transgenic leaves were stained with 4, 6-diamidino-2-phenylindole (DAPI). As shown in Figure 2, the green fluorescence of the control was localized in both in the nucleus and cytoplasm, and the 35S::NpFBA1-GFP signal was also observed in the cytoplasm and nucleus. This indicates that the NpFBA1 protein localized to the nucleus and cytoplasm.

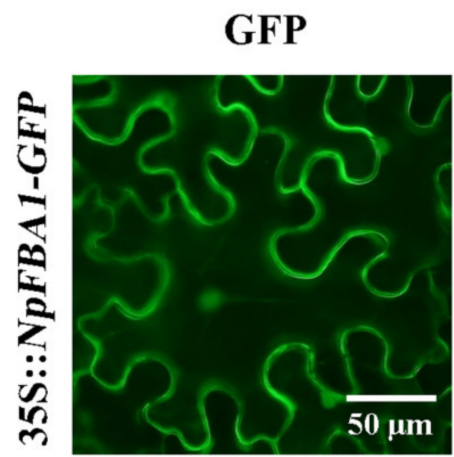

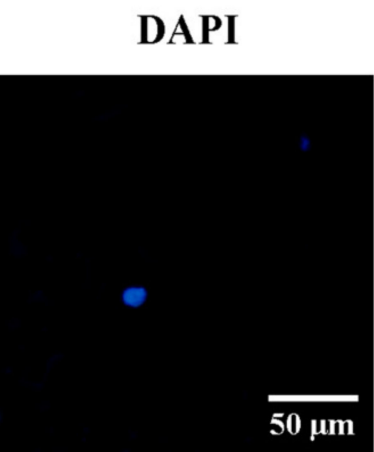

Bright field
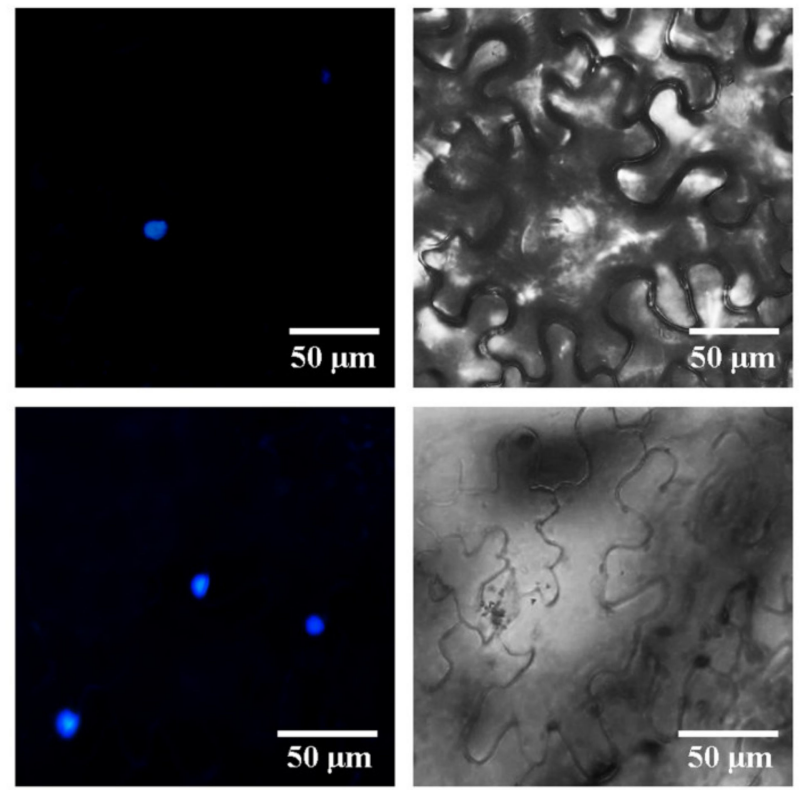

Merged
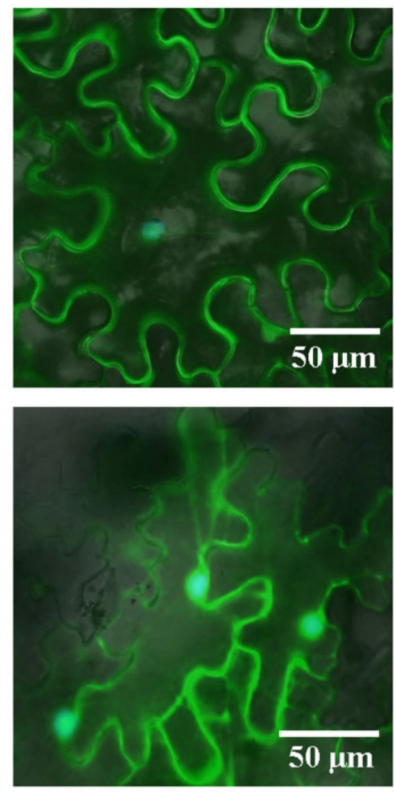

Figure 2. The subcellular localization of NPFBA1 in N. benthamiana epidermal cells. GFP: Green fluorescent protein. DAPI: Nucleic marker. Merged: Merged image of the bright field, GFP, and DAPI results. The above image is a random field of view taken from a fluorescent region of the tobacco epidermis. 


\subsection{NpFBA1 Responds to Pathogen Infection and Exogenous Hormones}

Based on previous studies, FBA genes may have a close relationship with disease resistance or sensitivity in plants. We treated N. plumbaginifolia with a spore suspension of P. parasitica and the $0.1 \% \mathrm{KNO}_{3}$ treatment as a control. qRT-PCR results showed that NpFBA1 was induced by pathogens within $0-72 \mathrm{~h}$, but this was a dynamic process. Compared with the control, NpFBA1 was not induced at $12 \mathrm{~h}$ and $18 \mathrm{~h}$, and the induced expression was the highest at 72h, 28.5 times that of the control (Figure 3A). The above results indicate that the NpFBA1 gene was responsive to infection by P. parasitica. We hypothesize that $N p F B A 1$ plays a role in the plant defense response.

Plant hormones play crucial roles in the regulation of the expression of defense genes and the reactions against biotic and abiotic stresses [32]. SA and MeJA are important signaling molecules in plants that activate downstream defense-related genes [33]. To explore whether NpFBA1 is involved in plant defense pathways. N. plumbaginifolia was treated with SA and MeJA, using the expression of $N p F B A 1$ in the untreated leaves as a control. $N$. plumbaginifolia treated with SA showed significantly higher $N p F B A 1$ expression between 6-72 $\mathrm{h}$, showing a tendency to rise, decrease, and rise again, with the highest expression after $72 \mathrm{~h}, 21$ times that of the control (Figure 3B). After MeJA treatment, NpFBA1 gene expression was suppressed at $6 \mathrm{~h}$ but induced at 48 and $72 \mathrm{~h}$, with the highest expression at 48 h, 2.3 times that of the control (Figure $3 C$ ). The above results indicate that the NpFBA1 gene responds to $\mathrm{SA}$ and MeJA hormone treatment and that $\mathrm{NpFBA1}$ responds more strongly to SA than MeJA.

A

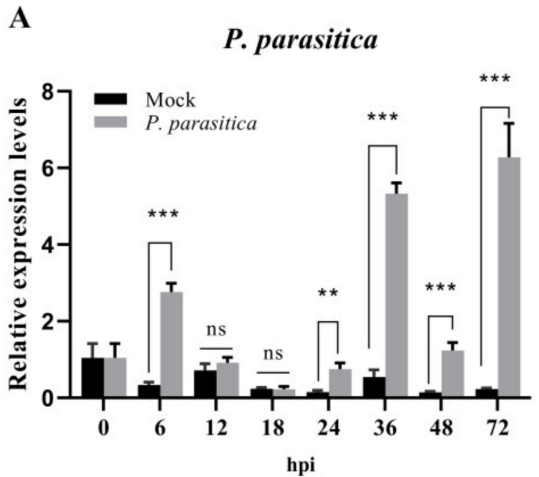

B

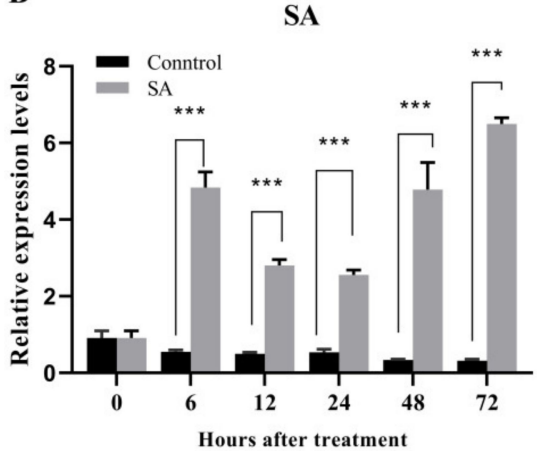

C MeJA

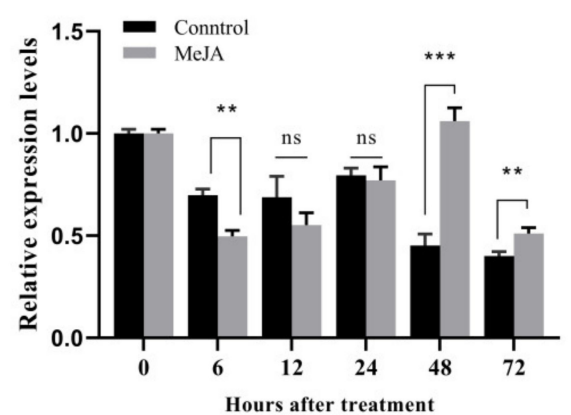

Figure 3. Transcript levels of NpFBA1 under treatment with P. parasitica, SA and MeJA. (A) Transcript levels of NpFBA1 under treatment with P. parasitica. (B) Transcript levels of NpFBA1 under treatment with SA. (C) Transcript levels of NpFBA1 under treatment with MeJA. Asterisks denote significant differences (compared with the control group): ${ }^{* *} p<0.01$, *** $p<0.001$, by Student's $t$-test; ns, no significant difference; number of samples, $\mathrm{n}=3$.

\subsection{Functional Identification of the NpFBA1 Gene}

To explore the function of $N p F B A 1$, we constructed a 35S::N $N F B A 1$ expression vector and then transformed it into common tobacco (N. tabacum). A total of $2335 \mathrm{~S}:: N p F B A 1$ transgenic lines were obtained by kanamycin screening and PCR identification (Supplementary Figure S1). Gene function was studied using three transgenic lines with increasing expression (Figure 4A).

\subsubsection{Effects of the NpFBA1 Gene on Tobacco Growth and Development}

To investigate the effect of the NpFBA1 gene on plant growth and development, we observed growth in WT and transgenic lines. During the rosette stage, most of the leaves of the transgenic tobacco were curled (Figure 4B), and the leaves of transgenic lines were more mature than those of the $\mathrm{WT}$, because we observed that NpFBA1\#2 showed shedding of hairs, drooping of leaf tips, hardening of leaves, and reduction of sticky substance on tobacco surface (Figure 4C). Curling of leaves, and plant dwarfing were also observed during the budding period of tobacco (Figure 4D). Moreover, leaf curling and 
plant dwarfism became more evident with the expression of the three transgenic lines. The above phenomena indicate that $N p F B A 1$ causes curling, aging and dwarfing of plant leaves.

A

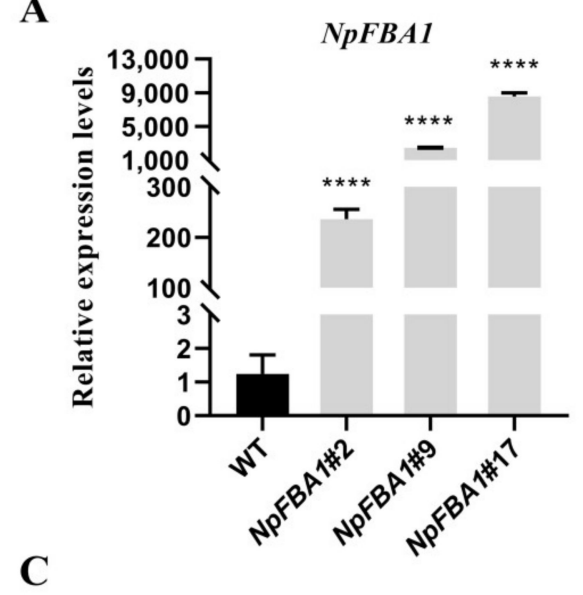

B

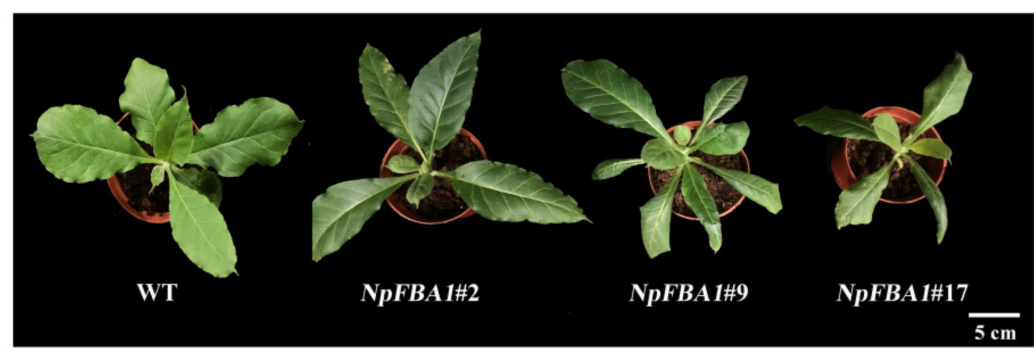

D

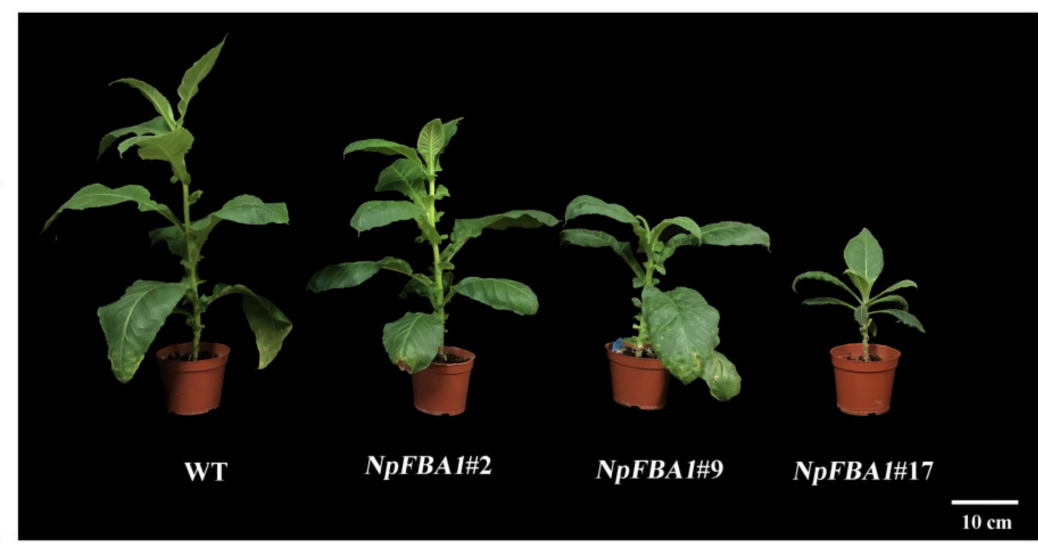

Figure 4. Expression analysis of $N p F B A 1$ and its effect on plant growth and development. (A) Expression levels of $N p F B A 1$ in both WT and transgenic plants, Asterisks indicate significant differences between WT and transgenic plants, ${ }^{* * * *} p<0.0001$, by Student's $t$-test, number of samples, $n=23$. $(\mathbf{B}, \mathbf{C})$ Leaf development of at the rosette stage in WT and transgenic plants.

(D) Stem length status of WT and transgenic plants.

The leaf morphology of the transgenic plants also changed significantly during the bolting stage, with more rounded leaves than those of the WT (Figure 5A,B). Leaf shape index (length/width) is an important parameter of leaf shape. The larger the leaf shape index of tobacco is, the longer and narrower the leaves are, while the smaller the leaf shape index is, the rounder the leaves are [34]. To verify whether the difference in leaf shape was significant, we measured the length and width of the fourth leaf from bottom to top and calculated the leaf shape index. The statistical results showed that the leaf shape index of the transgenic plants was significantly lower than that of the WT plants (Table 1), which indicated that the overexpression of NPFBA1 gene could lead to the change of tobacco leaf morphology. We speculated that was associated with the leaf curling phenotype.

Table 1. Comparison of leaf length, width and leaf shape index of NpFBA1-overexpressing and WT plants.

\begin{tabular}{cccc}
\hline Materials & Leaf Length $(\mathbf{c m})$ & Leaf Width $(\mathbf{c m})$ & Leaf Shape Index $($ Length/Width) \\
\hline WT & $19.33 \pm 2.35$ & $6.90 \pm 0.63$ & $2.81 \pm 0.03$ \\
NpFBA1\#2 & $16.00 \pm 1.75^{*}$ & $8.10 \pm 0.58$ & $2.02 \pm 0.01 *$ \\
NpFBA1\#9 & $17.80 \pm 0.28$ & $7.90 \pm 0.13$ & $2.29 \pm 0.02 *$ \\
NpFBA1\#17 & $17.16 \pm 0.58$ & $8.00 \pm 0.25$ & $2.15 \pm 0.01 *$ \\
\hline
\end{tabular}

Asterisks indicate significant differences between WT and transgenic plants, ${ }^{*} p<0.05$, by Student's $t$-test, number of samples, $\mathrm{n}=3$. 
A

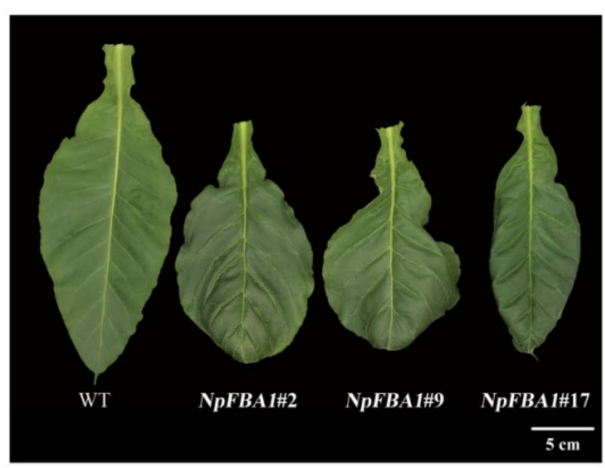

B

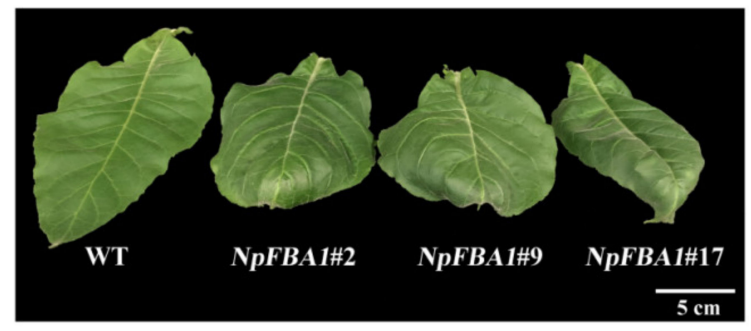

Figure 5. Effects of NpFBA1 on leaf morphology. (A,B) WT and transgenic plant leaf morphology.

\subsubsection{Observation of the Leaf Anatomical Structure of WT and Overexpressed Plants}

To further explore the cause of leaf curling of the transgenic lines, we took leaf tips from WT and transgenic lines for paraffin sections to observe the plant tissue structure of the leaf tips (Figure 6). We further counted the thickness of fence tissue, sponge tissue, upper epidermis cells, lower epidermal cells, the spongy ratio (SR), cell tense ratio (CTR), and fence tissue density (Supplementary Table S1) in the four lines, but only a few structures had significant differences (Table 2). Data analysis showed that several indicators of the overexpressing plants, including leaf thickness, superior epidermis thickness, sponge tissue thickness and fence tissue density, were significantly higher than WT, and the tissue structure tightness was lower compared with the control. Therefore, we speculate that the simultaneous increase in superior epidermal cell thickness and fence tissue tightness in overexpressing plants led to curling at the tip of tobacco leaves.

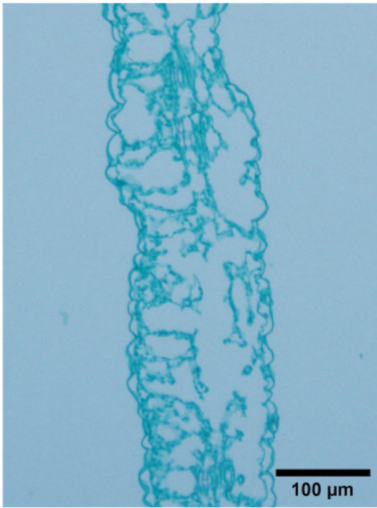

WT

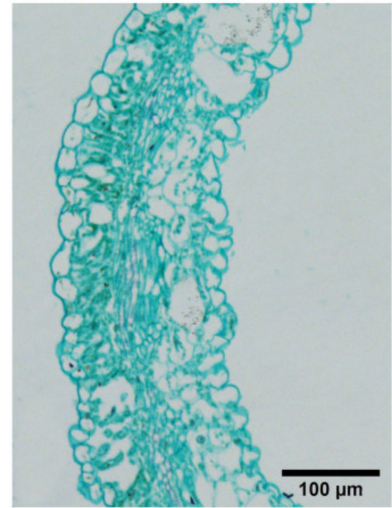

NpFBA1\#2

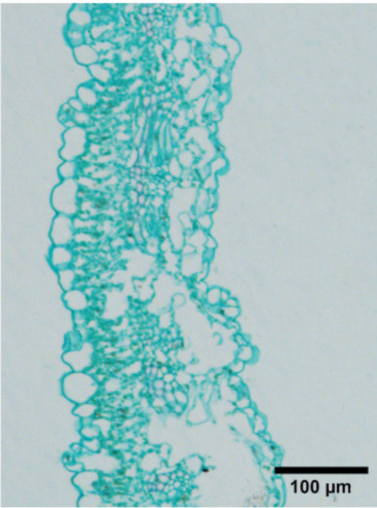

NpFBA1\#9

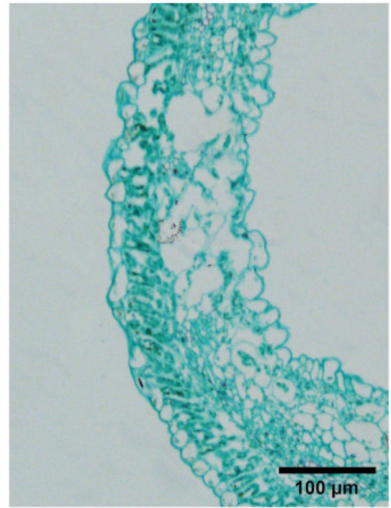

NpFBA1\#17

Figure 6. Comparison of anatomical structure of leaf tips of NpFBA1-overexpressing and WT plants.

Table 2. Comparison of anatomical structure indexes of NpFBA1-overexpressing and WT plants.

\begin{tabular}{cccccc}
\hline Materials & $\begin{array}{c}\text { Leaf Thickness } \\
(\boldsymbol{\mu})\end{array}$ & $\begin{array}{c}\text { Spongy Tissue } \\
\text { Thickness }(\boldsymbol{\mu m})\end{array}$ & $\begin{array}{c}\text { Upper Epidermis } \\
\text { Thickness }(\boldsymbol{\mu m})\end{array}$ & CTR\% & $\begin{array}{c}\text { Number of Cells per } \\
\mathbf{1} \text { mm Palisade Tissue }\end{array}$ \\
\hline WT & $177.25 \pm 5.27$ & $89.09 \pm 1.67$ & $10.30 \pm 1.78$ & $33.87 \pm 3.03$ & $44.33 \pm 5.13$ \\
NpFBA1\#2 & $210.17 \pm 18.25^{*}$ & $142.66 \pm 10.64^{* *}$ & $25.47 \pm 2.79^{* *}$ & $24.10 \pm 4.81^{*}$ & $57.00 \pm 1.73^{* *}$ \\
NpFBA1\#9 & $210.83 \pm 10.57^{* *}$ & $97.55 \pm 3.21^{*}$ & $24.14 \pm 1.80^{* *}$ & $22.72 \pm 4.99^{*}$ & $54.67 \pm 2.08^{*}$ \\
NpFBA1\#17 & $193.16 \pm 4.05^{*}$ & $128.96 \pm 8.61^{* *}$ & $22.64 \pm 2.95^{* *}$ & $19.60 \pm 0.67^{* *}$ & $70.33 \pm 4.16^{* *}$ \\
\hline
\end{tabular}

Asterisks indicate significant differences between WT and transgenic plants, ${ }^{*} p<0.05,{ }^{* *} p<0.01$, by Student's $t$-test, number of samples, $\mathrm{n}=3$. 


\subsubsection{Pathogen Infection Status}

Since NpFBA1 is highly expressed after infection by P. parasitica, we hypothesize that the NpFBA1 gene plays a role in the response to pathogen infection in plants. We used a spore suspension to inoculate leaves from plants overexpressing NpFBA1 and WT, and observed leaf damage. We found that during the tobacco rosette phase the transgenic line NpFBA1\#17 was more susceptible to disease than the control after low concentrations of spore suspension treatment (Figure 7A). Subsequently, we also performed in vitro pathogen infection experiments during the tobacco bolting stage. After 5 days of observation, we found that the transgenic lines were more susceptible than the WT plants. On the 5th day of infection, the spot area of the WT represented $2 / 3$ of the entire leaf, while the whole leaf of the transgenic lines were almost completely damaged (Supplementary Figure S2). We further measured the disease spot area across periods and found that the transgenic lines showed notably higher values than the WT plants on both the fourth and fifth days after inoculation with the spore suspension (Figure 7B). The above results suggest that the $N p F B A 1$ gene negatively regulates plant resistance, consistent with the findings of previous studies of NpFBA1 family genes.

A

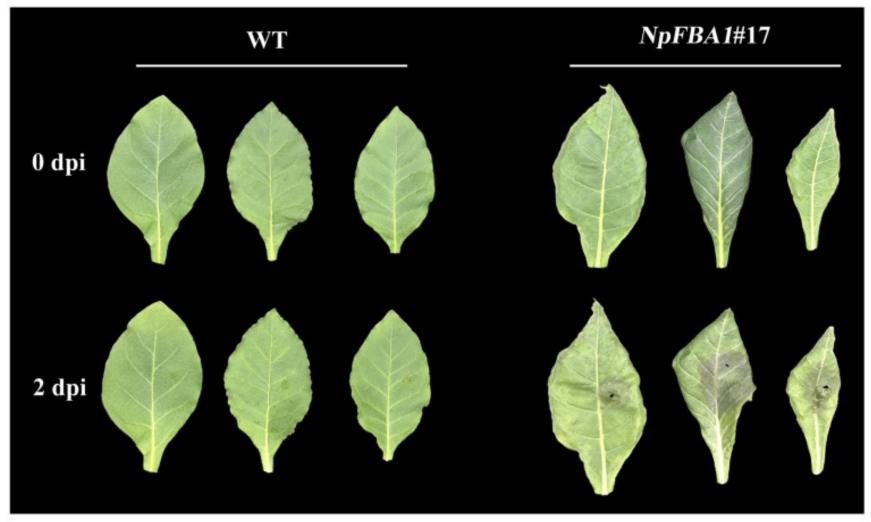

B

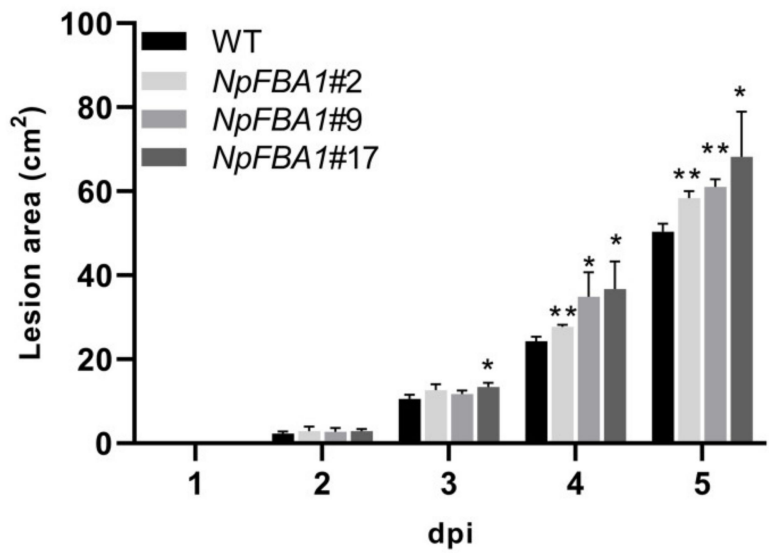

Figure 7. Effects of NpFBA1 on tobacco resistance to P. parasitica. (A) Leaf damage in the WT and transgenic lines at 0 and 2 days after $P$. parasitica infection. (B) Bar plot of leaf disease spot area from 0 to 5 days for the WT and transgenic lines. dpi, Days post inoculation. Asterisks indicate significant differences between WT and transgenic plants, ${ }^{*} p<0.05,{ }^{* *} p<0.01$, by Student's $t$-test, number of samples, $\mathrm{n}=3$.

Based on the dwarfism, leaf curling, and disease susceptibility phenotypes present in the transgenic lines, we hypothesized that leaf development-related genes (NtARF2, NtARF3 and NtPRTa) [35-37], the negative regulator gene of the GA pathway NtDALLE [38], and lignin synthesis genes (NtPAL, NtC4H,NtCAD2 and NtCCR1) [39], may be affected. We further examined the expression changes of the above genes in transgenic lines and WT plants (Figure 8). The results showed that the expression of auxin response factor $N t A R F 2$ regulating leaf maturation was significantly increased compared to that in WT plants; NtARF3 and NtPRTa genes involved in leaf morphogenesis were significantly down-regulated; the expression of NtDALLE, a negative regulator of the GA pathway, was significantly increased; and the expression of lignin synthesis-related genes $(N t P A L, N t C 4 H$, $N t C A D 2$ and NtCCR1) was significantly reduced in transgenic lines. These results suggest that the NpFBA1 gene influences tobacco plant height and leaf development by affecting the auxin, gibberellin, and lignin signaling pathways. 

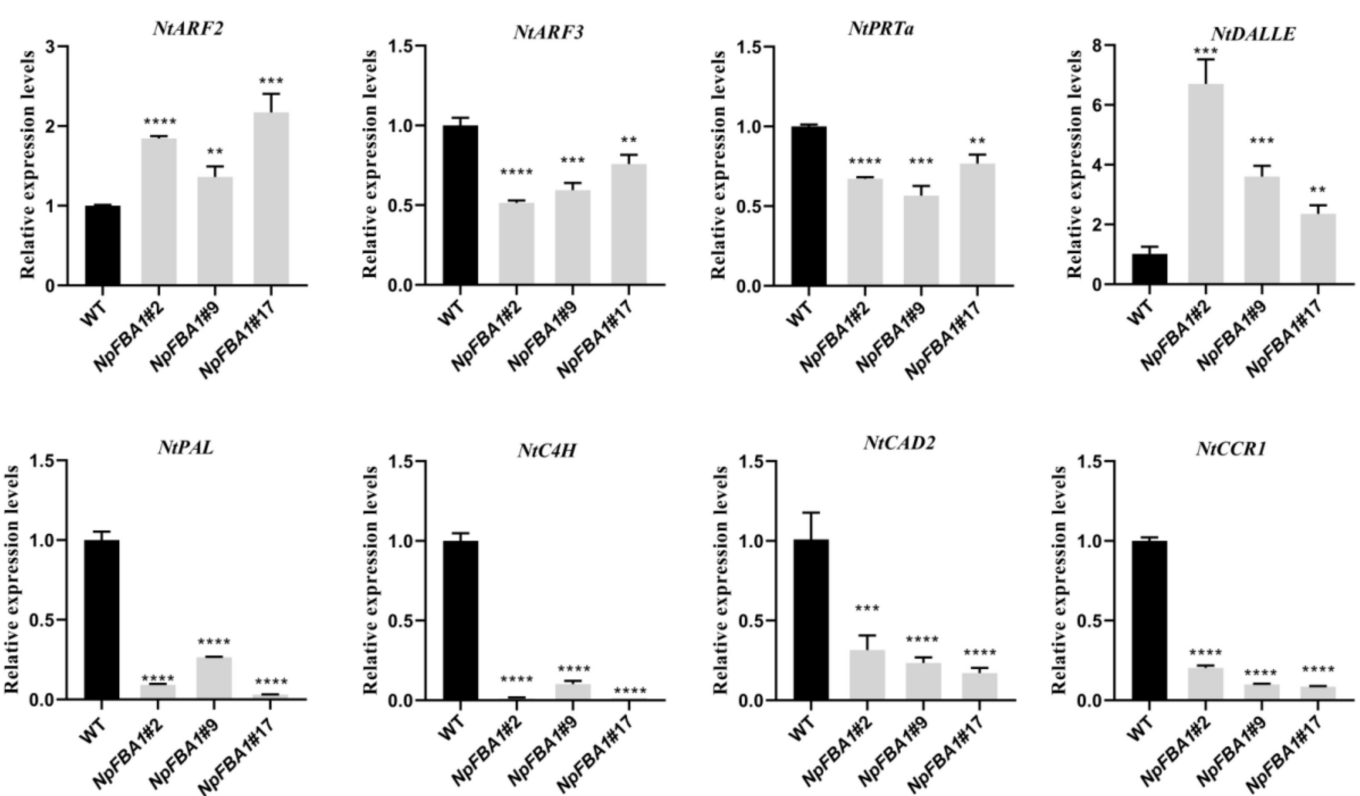

Figure 8. Expression levels of genes associated with growth and development of the WT and transgenic lines. Asterisks indicate significant differences between WT and transgenic plants, ${ }^{* *} p<0.01,{ }^{* * *} p<0.001,{ }^{* * *} p<0.0001$, by Student's $t$-test, number of samples, $\mathrm{n}=3$.

\section{Discussion}

Leaf morphology has a great impact on plant drought resistance, ornamental research and leaf yield [40-42]. Although many genes $[43,44]$ have been identified in plants that maintain proper leaf morphology, the genes directly controlling leaf shape, especially leaf curling, are unknown. Previous studies have shown that the 26S proteasomal degradation pathway mediated by the F-box protein is required for leaf development [45], and its secondary FBA domain is key for binding to downstream target proteins, but no functional studies of the FBA domain in tobacco have been performed. In this study, we isolated the gene $N p F B A 1$ from N. plumbaginifolia to explore its potential role in leaf morphological development. Multiple alignment of NpFBA1 amino acid sequences with sequences from other species and phylogenetic analysis showed that $N p F B A 1$ is in a separate clade from other tobacco FBA genes, mainly due to the absence of the F-box domain of NpFBA1 compared with other solanaceae plants. Subcellular localization experiments revealed that the $N p F B A 1$ protein is localized to the nucleus and cytoplasm, consistent with previous findings in Arabidopsis [22]. Overexpression of the NpFBA1 gene leads to leaf curling, and plant dwarfing, providing a molecular basis for further studying the agronomic trait of plant leaf curling.

Auxin, a major regulator of cell proliferation, plays a crucial role in leaf morphogenesis and morphogenesis [46]. Thus, genetic modifications involving auxin homeostasis can lead to pleiotropic developmental defects, including leaf abnormalities. ARF is a key transcription factor regulating auxin signaling, and the ARF2 gene has been reported to regulate leaf senescence with floral organ shedding [35]. ARF3 physically interacts with the KANADI protein to form a functional complex essential for the maintenance of epidermal development and near-distal axis polarity in Arabidopsis [36]. In the NpFBA1overexpressing plants, leaf senescence related gene $N t A R F 2$ expression was significantly upregulated, we hypothesized that this might cause premature leaf senescence in transgenic plants. On the contrary, NtARF3 and Nt NtPRTa genes involved in leaf morphogenesis were significantly down-regulated, which may lead to leaf curl. In addition, we believe that significant downregulation of NtARF3 in transgenic tobacco leads to abnormal auxin production, which leads to abnormal development of leaf shape and plant height.

We found that the $N p F B A 1$ gene was expressed in response to treatment with exogenous hormones (SA and MeJA) and P. parasitica, similar to the results for most F-box genes, 
such as BIG-24.1, TaPP2-A13, and TaFKOR23 [47-49]. Therefore, we hypothesized that this gene plays a role in plant-pathogen interactions. Interestingly, overexpression of the NpFBA1 gene did not enhance tobacco resistance to black shank disease, but instead attenuated its resistance, and these results were similar to those presented for the soybean NLL gene. The expression of GmNLL1 and GmNLL2 in soybean was significantly upregulated after infection with Phytophthora; however, overexpression of GmNLL1 and GmNLL2 in Arabidopsis did not enhance plant resistance to Phytophthora [50].

Notably, the regulatory immune regulatory pathway of the $N p F B A 1$ gene in this study is likely different from that previously reported for $C P R 1 / C P R 30$, and since the $N p F B A 1$ gene has no conserved F-box domain, it likely does not trigger the degradation of the ubiquitin proteasome for the $\mathrm{R}$ protein. The plant susceptibility response mediated by the FBA gene is more likely to be caused by leaf aging and reduced lignin synthesis. Decreased activity of the reactive oxygen species scavenger superoxide dismutase (SOD) and accumulated reactive oxygen species in aging leaves can easily cause membrane lipid de-esterification, causing damage to the membrane structure and making pathogens more likely to invade plant cells. Lignin is a major component of the plant cell wall capable of protection against various biotic and abiotic stresses. It acts as a physical and chemical barrier to limit pathogen colonization and to limit pathogen growth in a variety of plants, and lignin has been used as a biochemical marker for detecting activated immunity [51]. phenylalanine ammonia-lyase (PAL), cinnamoyl CoA reductase (CCR), cinnamyl alcohol dehydrogenase $(\mathrm{CAD})$, and cinnamate 4-hydroxylase $(\mathrm{C} 4 \mathrm{H})$ are all key enzyme in the lignin synthesis pathway [39], and all four are severely downregulated in plants overexpressing $N p F B A 1$, perhaps further leading to dwarfing and susceptibility in tobacco plants.

The current study of FBA gene-protein interactions has focused on the F-box motif at the N-terminus. The FBA gene family is often involved in the ubiquitin protease pathway through SKP1 binding to the F-box conserved domain, while target proteins at the $\mathrm{C}$ end of the F-box protein are very poorly reported. In Arabidopsis, some target proteins of FBA family genes have been reported, EIN3-BINDING F-BOX 1 (EBF1) regulate the plant ethylene pathway and promote plant frost resistance by targeting the proteins ETHYLENE INSENSITIVE3 (EIN3) and PHYTOCHROME-INTERACTING FACTOR 3 (PIF3) [52,53]. The Arabidopsis $A B A$-responsive FBA domain-containing protein 1 (AFBA1) gene combines with the transcription factors MYB44, TCP4 and TCP14 to regulate the ABA pathway [21]. The Arabidopsis CPR1/CPR30 protein interacts with the R proteins suppressor of npr1 constitutive1 (SNC1)and NBS-LRR protein (RPS2) and then degrades the R protein through the ubiquitin proteasome pathway to negatively regulate plant resistance. The diversity of FBA domain targets leads to the regulation of various aspects of the plant. Finding targets of the F-box protein is important for demonstrating its regulation of various aspects of plant growth and development. FBA motifs in F-box proteins function as identifying substrates and are essential for the normal function of F-box proteins, but the targets of most FBA genes and their functions are unknown.

Based on our results as well as the results of earlier studies, we conjectured that $N p F B A 1$ and many uncharacterized F-box proteins containing functional FBA motifs share their target transcription repressors (TRs) involved in the negative regulation of various hormone response pathways, such as the auxin repressor Aux/IAA [54], and GA negative regulator DALLE [38]. On the one hand, the $N p F B A 1$ protein competitively binds common targets downstream of the F-box-containing FBA protein so that this target protein cannot be recognized by FBA containing the F-box protein for UPS-mediated protein degradation. This suppresses the ubiquitin protease degradation pathway essential for plant growth and development, finally leading to abnormal plant growth and development; on the other hand, NpFBA1 may bind to unknown TRs and directly cause a decline in downstream lignin synthesis genes, resulting in reduced plant resistance to pathogens (Figure 9). However, the specific mechanisms by which $N p F B A 1$ causes plant leaf curling remain to be investigated. 


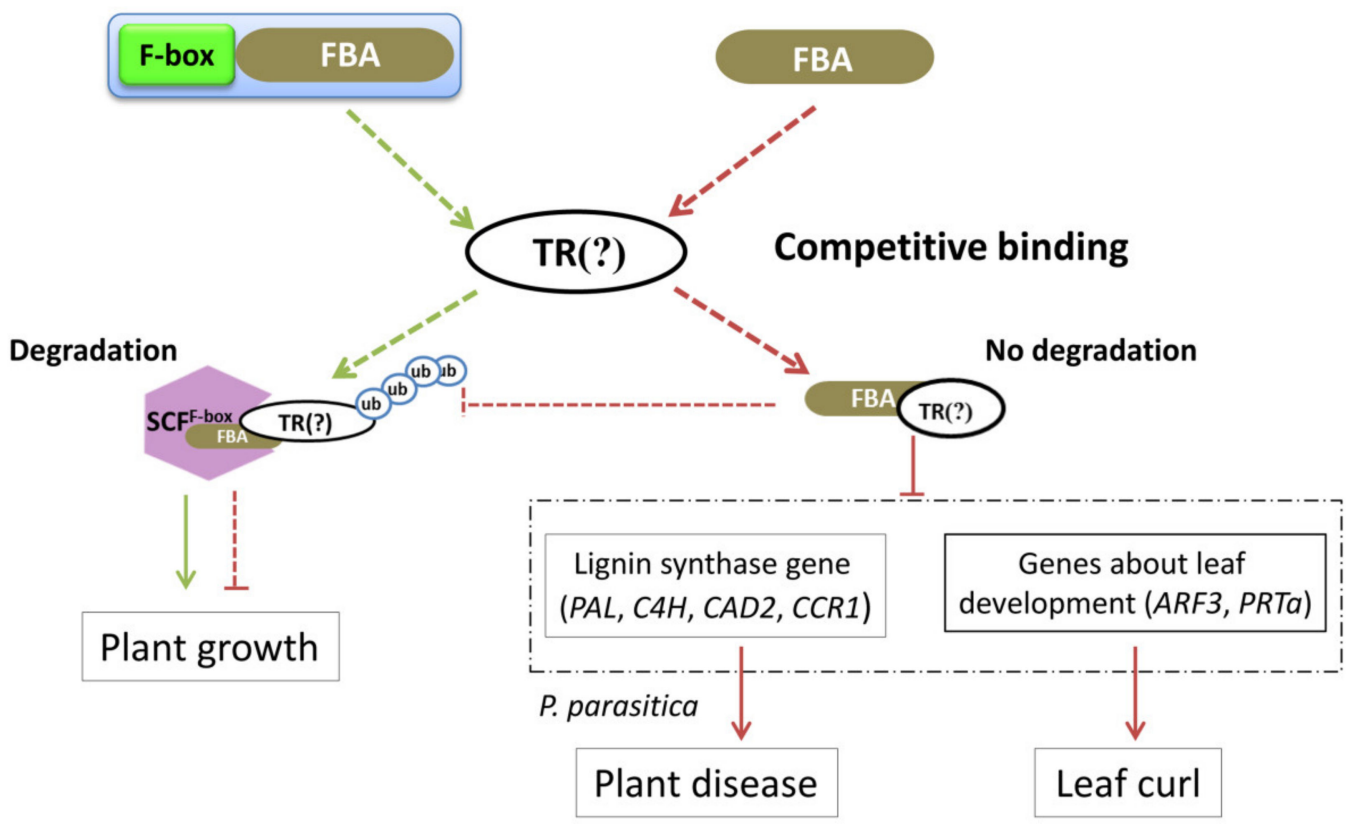

Figure 9. Putative model of FBA gene regulation of plant growth. Green lines represent the false regulatory pathway of the FBA gene containing the F-box protein, and red lines represent the regulatory pathway of the FBA gene containing only the FBA domain. The T-lines and arrows indicate inhibition and promotion, respectively. Solid line: red is the result of our experiment, green is the result of previous studies; Dotted line: the pathway we speculate. TR(?): unknown target transcription repressors, SCF: the complex of SKP1, CUL1 and RBX.

\section{Conclusions}

In this study, the NpFBA1 gene was located in the nucleus and cytoplasm and associated with leaf curling. Overexpression of $N p F B A 1$ causes leaf curling and dwarfing of plants. Furthermore, we observed that overexpression of NpFBA1 led to tobacco susceptibility prone P. parasitica. Leaf anatomical analysis showed that superior epidermal cell thickness and fence tissue density were significantly higher than WT, and we speculate that this was one of the causes of leaf curl. Gene expression associated with lignin synthesis was significantly decreased in $N p F B A 1$ overexpressing plants, leading to tobacco susceptibility to black shank disease. Although the NpFBA1 gene is strongly induced by P. parasitica and SA, it attenuates tobacco resistance to $P$. parasitica, which cannot be explained in our study. Our data provide insights into NpFBA1 regulation of tobacco leaf curl with pathogen defense, whereas the specific regulatory mechanisms remain to be further investigated.

Supplementary Materials: The following are available online at https:/ / www.mdpi.com/article/ 10.3390/agronomy11122478/s1: Figure S1: Screening NpFBA1 transgenic lines; Figure S2: Leaf damage in the WT and transgenic lines at 0-5 days after P. parasitica infection; Table S1: Comparison of anatomical structure indexes of NpFBA1-overexpressing and WT plants; Table S2: Primers used for gene cloning; Table S3: Names and accession numbers used for phylogenetic analysis; Table S4: Primers used for vector construction; and Table S5: Primers used for quantitative real-time PCR (qRT-PCR).

Author Contributions: Conceptualization, Z.X., J.D. and G.L.; methodology, Z.X. and C.L.; software, G.W. and H.W.; validation, Y.Y. and J.W.; formal analysis, G.W.; investigation, Z.X. and G.W.; resources, J.D. and G.L.; data curation, Z.X. and G.W.; writing-original draft preparation, Z.X.; writing-review and editing, J.D. and G.W., visualization, Y.Y.; supervision, G.L.; project administration, J.D. and Q.G.; and funding acquisition, J.D., Q.G. and G.L. All authors have read and agreed to the published version of the manuscript.

Funding: This research was funded by Chongqing Science and Technology Project of China National Tobacco Corporation (No. NY20170401070001).

Institutional Review Board Statement: Not applicable. 
Informed Consent Statement: Not applicable.

Data Availability Statement: NpFBA1 sequence data is available in GenBank.

Conflicts of Interest: The authors declare no conflict of interest.

\section{References}

1. Sadanandom, A.; Bailey, M.; Ewan, R.; Lee, J.; Nelis, S. The ubiquitin-proteasome system: Central modifier of plant signalling. New Phytol. 2012, 196, 13-28. [CrossRef] [PubMed]

2. Bai, C.; Sen, P.; Hofmann, K.; Ma, L.; Goebl, M.; Harper, J.W.; Elledge, S.J. SKP1 connects cell cycle regulators to the ubiquitin proteolysis machinery through a novel motif, the F-box. Cell 1996, 86, 263-274. [CrossRef]

3. Lechner, E.; Achard, P.; Vansiri, A.; Potuschak, T.; Genschik, P. F-box proteins everywhere. Curr. Opin. Plant Biol. 2006, 9, 631-638. [CrossRef]

4. Kuroda, H.; Takahashi, N.; Shimada, H.; Seki, M.; Shinozaki, K.; Matsui, M. Classification and expression analysis of Arabidopsis F-Box-Containing protein genes. Plant Cell Physiol. 2002, 43, 1073-1085. [CrossRef] [PubMed]

5. Kipreos, E.T.; Pagano, M. The F-box protein family. Genome Biol. 2000, 1, REVIEWS3002. [CrossRef] [PubMed]

6. Schumann, N.; Navarro-Quezada, A.; Ullrich, K.; Kuhl, C.; Quint, M. Molecular evolution and selection patterns of plant F-box proteins with C-terminal kelch repeats. Plant Physiol. 2011, 155, 835-850. [CrossRef] [PubMed]

7. Ariizumi, T.; Hauvermale, A.L.; Nelson, S.K.; Hanada, A.; Yamaguchi, S.; Steber, C.M. Lifting della repression of Arabidopsis seed germination by nonproteolytic gibberellin signaling. Plant Physiol. 2013, 162, 2125-2139. [CrossRef]

8. Wen, C.K.; Chang, C. Arabidopsis RGL1 encodes a negative regulator of gibberellin responses. Plant Cell 2002, 14, 87-100. [CrossRef] [PubMed]

9. Tyler, L.; Thomas, S.G.; Hu, J.; Dill, A.; Alonso, J.M.; Ecker, J.R.; Sun, T. Della proteins and gibberellin-regulated seed germination and floral development in Arabidopsis. Plant Physiol. 2004, 135, 1008-1019. [CrossRef]

10. Fu, X.; Richards, D.E.; Fleck, B.; Xie, D.; Burton, N.; Harberd, N.P. The Arabidopsis mutant sleepy19ar2-1 protein promotes plant growth by increasing the affinity of the $\mathrm{SCF}^{\mathrm{SLY} 1} \mathrm{E} 3$ ubiquitin ligase for DELLA protein substrates. Plant Cell 2004, 16, 1406-1418. [CrossRef]

11. Gomi, K.; Sasaki, A.; Itoh, H.; Ueguchi-Tanaka, M.; Ashikari, M.; Kitano, H.; Matsuoka, M. GID2, an F-box subunit of the SCF E3 complex, specifically interacts with phosphorylated SLR1 protein and regulates the gibberellin-dependent degradation of SLR1 in rice. Plant J. 2004, 37, 626-634. [CrossRef]

12. Xing, L.; Li, Z.; Khalil, R.; Ren, Z.; Yang, Y. Functional identification of a novel F-box/FBA gene in tomato. Physiol. Plant. 2012, 144, 161-168. [CrossRef] [PubMed]

13. Dharmasiri, N.; Dharmasiri, S.; Estelle, M. The F-box protein TIR1 is an auxin receptor. Nature 2005, 435, 441-445. [CrossRef] [PubMed]

14. Chapman, E.J.; Estelle, M. Mechanism of auxin-regulated gene expression in plants. Annu. Rev. Genom. Hum. Genet. 2009, 43, 265-285. [CrossRef] [PubMed]

15. Qin, G.; Gu, H.; Zhao, Y.; Ma, Z.; Shi, G.; Yang, Y.; Pichersky, E.; Chen, H.; Liu, M.; Chen, Z.; et al. An indole-3-acetic acid carboxyl methyltransferase regulates Arabidopsis leaf development. Plant Cell 2005, 17, 2693-2704. [CrossRef] [PubMed]

16. Cheng, Y.; Dai, X.; Zhao, Y. Auxin biosynthesis by the YUCCA flavin monooxygenases controls the formation of floral organs and vascular tissues in Arabidopsis. Gene Dev. 2006, 20, 1790-1799. [CrossRef]

17. Song, J.B.; Huang, S.Q.; Dalmay, T.; Yang, Z.M. Regulation of leaf morphology by MicroRNA394 and its target LEAF CURLING RESPONSIVENESS. Plant Cell Physiol. 2012, 53, 1283-1294. [CrossRef]

18. Hu, Z.; Keceli, M.A.; Piisilä, M.; Li, J.; Survila, M.; Heino, P.; Brader, G.; Palva, E.T.; Li, J. F-box protein AFB4 plays a crucial role in plant growth, development and innate immunity. Cell Res. 2012, 22, 777-781. [CrossRef]

19. Han, B.; Chen, L.; Wang, J.; Wu, Z.; Yan, L.; Hou, S. Constitutive expresser of pathogenesis related genes 1 Is required for pavement cell morphogenesis in Arabidopsis. PLoS ONE 2015, 10, e0133249. [CrossRef]

20. Qiao, H.; Chang, K.N.; Yazaki, J.; Ecker, J.R. Interplay between ethylene, ETP1/ETP2 F-box proteins, and degradation of EIN2 triggers ethylene responses in Arabidopsis. Genes Dev. 2009, 23, 512-521. [CrossRef]

21. Kim, Y.Y.; Cui, M.H.; Noh, M.S.; Jung, K.W.; Shin, J.S. The FBA motif-containing protein AFBA1 acts as a novel positive regulator of ABA response in Arabidopsis. Plant Cell Physiol. 2017, 58, 574-586. [CrossRef] [PubMed]

22. Gou, M.; Su, N.; Zheng, J.; Huai, J.; Wu, G.; Zhao, J.; He, J.; Tang, D.; Yang, S.; Wang, G. An F-box gene, CPR30, functions as a negative regulator of the defense response in Arabidopsis. Plant J. 2009, 60, 757-770. [CrossRef] [PubMed]

23. Kim, H.S.; Delaney, T.P. Arabidopsis SON1 is an F-Box protein that regulates a novel induced defense response independent of both salicylic acid and systemic acquired resistance. Plant Cell 2002, 14, 1469-1482. [CrossRef] [PubMed]

24. Gou, M.; Shi, Z.; Zhu, Y.; Bao, Z.; Wang, G.; Hua, J. The F-box protein CPR1/CPR30 negatively regulates R protein SNC1 accumulation. Plant J. 2012, 69, 411-420. [CrossRef] [PubMed]

25. Grappin, P.; Bouinot, D.; Sotta, B.; Miginiac, E.; Jullien, M. Control of seed dormancy in Nicotiana plumbaginifolia: Post-imbibition abscisic acid synthesis imposes dormancy maintenance. Planta 2000, 210, 279-285. [CrossRef] 
26. Dang, J.; Wang, J.; Yang, Y.; Shang, W.; Guo, Q.; Liang, G. Resistance of Nicotiana tabacum to Phytophthora parasitica var. nicotianae race 0 is enhanced by the addition of $N$. plumbaginifolia chromosome 9 with a slight effect on host genomic expression. Crop Sci. 2019, 59, 2667-2678. [CrossRef]

27. Hoekema, A.; Hirsch, P.R.; Hooykaas, P.J.J.; Schilperoort, R.A. A binary plant vector strategy based on separation of vir- and T-region of the Agrobacterium tumefaciens Ti-plasmid. Nature 1983, 303, 179-180. [CrossRef]

28. Wen, G.; Dang, J.; Xie, Z.; Wang, J.; Jiang, P.; Guo, Q.; Liang, G. Molecular karyotypes of loquat (Eriobotrya japonica) aneuploids can be detected by using SSR markers combined with quantitative PCR irrespective of heterozygosity. Plant Methods 2020, 16, 22. [CrossRef]

29. Livak, K.J.; Schmittgen, T.D. Analysis of relative gene expression data using real-time quantitative PCR and the $2^{-\triangle \triangle C T}$ method. Methods 2001, 25, 402-408. [CrossRef]

30. Schmidt, G.W.; Delaney, S.K. Stable internal reference genes for normalization of real-time RT-PCR in tobacco (Nicotiana tabacum) during development and abiotic stress. Mol. Genet. Genom. 2010, 283, 233-241. [CrossRef]

31. Dang, J.; Wu, T.; Liang, G.; Wu, D.; He, Q.; Guo, Q. Identification and characterization of a loquat aneuploid with novel leaf phenotypes. HortScience 2019, 54, 1-5. [CrossRef]

32. Liu, Y.; Liu, Q.; Tang, Y.; Ding, W. NtPR1a regulates resistance to Ralstonia solanacearum in Nicotiana tabacum via activating the defense-related genes. Biochem. Biophys. Res. Commun. 2019, 508, 940-945. [CrossRef] [PubMed]

33. Tang, Y.; Kuang, J.; Wang, F.; Chen, L.; Hong, K.; Xiao, Y.; Xie, H.; Lu, W.; Chen, J. Molecular characterization of PR and WRKY genes during SA- and MeJA-induced resistance against Colletotrichum musae in banana fruit. Postharv. Biol. Technol. 2013, 79, 62-68. [CrossRef]

34. Li, Q.; Wang, S.; Liu, G.; Zhou, P.; Zheng, X.; Ceng, W.; Chen, Z.; Chen, A. Response of tobacco leaf shape index and auxin to low temperature stress and growth recovery. Jiangsu Agric. Sci. 2019, 47, 60-65. [CrossRef]

35. Ellis, C.M.; Nagpal, P.; Young, J.C.; Hagen, G.; Guilfoyle, T.J.; Reed, J.W. AUXIN RESPONSE FACTOR1 and AUXIN RESPONSE FACTOR2 regulate senescence and floral organ abscission in Arabidopsis thaliana. Development 2005, 132, 4563-4574. [CrossRef]

36. Kelley, D.R.; Arreola, A.; Gallagher, T.L.; Gasser, C.S. ETTIN (ARF3) physically interacts with KANADI proteins to form a functional complex essential for integument development and polarity determination in Arabidopsis. Development 2012, 139, 1105-1109. [CrossRef]

37. Sonoda, Y.; Sako, K.; Maki, Y.; Yamazaki, N.; Yamamoto, H.; Ikeda, A.; Yamaguchi, J. Regulation of leaf organ size by the Arabidopsis RPT2a 19S proteasome subunit. Plant J. 2009, 60, 68-78. [CrossRef]

38. Fu, X.; Richards, D.E.; Ait-ali, T.; Hynes, L.W.; Ougham, H.; Peng, J.; Harberd, N.P. Gibberellin-mediated proteasome-dependent degradation of the barley DELLA protein SLN1 repressor. Plant Cell 2002, 14, 3191-3200. [CrossRef] [PubMed]

39. Humphreys, J.M.; Chapple, C. Rewriting the lignin roadmap. Curr. Opin. Plant Biol. 2002, 5, 224-229. [CrossRef]

40. Li, G.; Zhang, K.; Liu, F.; Liu, D.; Wan, Y. Morphological and physiological traits of leaf in different drought resistant peanut cultivars. Sci. Agric. Sin. 2014, 47, 644-654. [CrossRef]

41. Feng, X.; Li, X.; Yang, X.; Zhu, P. Fine mapping and identification of the leaf shape gene BoFL in ornamental kale. Theor. Appl. Genet. 2020, 133, 1303-1312. [CrossRef] [PubMed]

42. Gu, Y.; Cheng, S.; Dou, Y.; Xie, Y.; Liu, G.; Liu, X.; Du, Y. Relationship between leaf shape and inner quality of Flue-cured Tobacco in Xuanwei County of Yunnan Province. Chin. Tob. Sci. 2011, 32, 6-13. [CrossRef]

43. Robles, P.; Fleury, D.; Candela, H.; Cnops, G.; Alonso-Peral, M.M.; Anami, S.; Falcone, A.; Caldana, C.; Willmitzer, L.; Ponce, M.R.; et al. The RON1/FRY1/SAL1 gene is required for leaf morphogenesis and venation patterning in Arabidopsis. Plant Physiol. 2010, 152, 1357-1372. [CrossRef] [PubMed]

44. Chen, Y.; Dan, Z.; Gao, F.; Chen, P.; Fan, F.; Li, S. Rice GROWTH-REGULATING FACTOR7 modulates plant architecture through regulating GA and Indole-3-Acetic acid metabolism. Plant Physiol. 2020, 184, 393-406. [CrossRef] [PubMed]

45. Huang, W.; Pi, L.; Liang, W.; Xu, B.; Wang, H.; Cai, R.; Huang, H. The proteolytic function of the Arabidopsis $26 \mathrm{~S}$ proteasome is required for specifying leaf adaxial identity. Plant Cell 2006, 18, 2479-2492. [CrossRef]

46. Zhang, Z.; Runions, A.; Mentink, R.A.; Kierzkowski, D.; Karady, M.; Hashemi, B.; Huijser, P.; Strauss, S.; Gan, X.; Ljung, K.; et al. A WOX/Auxin biosynthesis module controls growth to shape leaf form. Curr. Biol. 2020, 30, 4857-4868.e6. [CrossRef]

47. Paquis, S.; Mazeyrat-Gourbeyre, F.; Fernandez, O.; Crouzet, J.; Clément, C.; Baillieul, F.; Dorey, S. Characterization of a F-box gene up-regulated by phytohormones and upon biotic and abiotic stresses in grapevine. Mol. Biol. Rep. 2011, 38, 3327-3337. [CrossRef]

48. Meng, Y.; Wei, C.; Fan, R.; Yu, X.; Wang, X.; Zhao, W.; Wei, X.; Kang, Z.; Liu, D. TaPP2-A13 gene shows induced expression pattern in wheat responses to stresses and interacts with adaptor protein SKP1 from SCF complex. Acta Agron. Sin. 2021, 47, 224-236. [CrossRef]

49. Wei, C.; Meng, Y.; Fan, R.; Zhao, M.; Yu, X.; Zhao, W.; Kang, Z.; Liu, D. Stress-related expression profile of F-box/Kelch gene TaFKOR23 in wheat and molecular characterization of the interacting target protein. J. Plant Genet. Resour. 2020, 21, 695-705. [CrossRef]

50. Holle, S.V.; Smagghe, G.; Damme, E.J.M.V. Overexpression of Nictaba-Like Lectin genes from Glycine max confers tolerance toward Pseudomonas syringae infection, aphid infestation and salt stress in transgenic Arabidopsis plants. Front Plant Sci. 2016, 7, 1590. [CrossRef] 
51. Hou, J.; Zhao, F.; Yang, X.; Li, W.; Xie, D.; Tang, Z.; Lv, S.; Nie, L.; Sun, Y.; Wang, M.; et al. Lignin synthesis related genes with potential significance in the response of upland cotton to fusarium wilt identified by transcriptome profiling. Trop. Plant Biol. 2021, 14, 106-119. [CrossRef]

52. An, F.; Zhao, Q.; Ji, Y.; Li, W.; Jiang, Z.; Yu, X.; Zhang, C.; Han, Y.; He, W.; Liu, Y.; et al. Ethylene-induced stabilization of ETHYLENE INSENSITIVE3 and EIN3-LIKE1 is mediated by proteasomal degradation of EIN3 binding F-Box 1 and 2 that requires EIN2 in Arabidopsis. Plant Cell 2010, 22, 2384-2401. [CrossRef] [PubMed]

53. Jiang, B.; Shi, Y.; Zhang, X.; Xin, X.; Qi, L.; Guo, H.; Li, J.; Yang, S. PIF3 is a negative regulator of the CBF pathway and freezing tolerance in Arabidopsis. Proc. Natl. Acad. Sci. USA 2017, 114, E6695-E6702. [CrossRef] [PubMed]

54. Grones, P.; Friml, J. Auxin transporters and binding proteins at a glance. J. Cell Sci. 2015, 128, 1-7. [CrossRef] [PubMed] 